\title{
Extended Criteria Donors in Living Kidney Transplantation Including Donor Age, Smoking, Hypertension and BMI
}

This article was published in the following Dove Press journal:

Therapeutics and Clinical Risk Management

Henning Plage,' Poline Pielka,' Lutz Liefeldt, ${ }^{2}$ Klemens Budde, ${ }^{2}$ Jan Ebbing, ${ }^{3}$ Nesrin Sugünes,' Kurt Miller,' Hannes Cash,' Anna Bichmann, (1D) Arne Sattler, ${ }^{5}$ Katja Kotsch, ${ }^{5}$ Frank Friedersdorff'

'Department of Urology, Charité Universitätsmedizin Berlin, Corporate Member of Freie Universität Berlin, Humboldt-Universität zu Berlin, Berlin Institute of Health, Berlin, Germany; ${ }^{2}$ Department of Nephrology, Charité Universitätsmedizin Berlin, Corporate Member of Freie Universität Berlin, Humboldt-Universität zu Berlin, Berlin Institute of Health, Berlin, Germany; ${ }^{3}$ Department of Urology, University Hospital Basel, Urological University Clinic Basel-Liestal, Basel, Switzerland; ${ }^{4}$ Department of Anaesthesia and Operative Intensive Care Medicine, Charité Universitätsmedizin Berlin, Corporate Member of Freie Universität Berlin, Humboldt-Universität zu Berlin, Berlin Institute of Health, Berlin, Germany;

${ }^{5}$ Department of General, Visceral- and Vascular Surgery, Charité -

Universitätsmedizin Berlin, Corporate Member of Freie Universität Berlin, Humboldt-Universität zu Berlin, Berlin, Germany

Correspondence: Frank Friedersdorff Department of Urology, Charité Universitätsmedizin Berlin, Corporate Member of Freie Universität Berlin, Humboldt-Universität zu Berlin, Berlin Institute of Health, Charitéplatz I, Berlin 10117, Germany

Tel +4930450615219

Fax +4930450515910

Email frank.friedersdorff@charite.de
Purpose: An expansion of selection criteria for deceased organ transplantation already exists to manage the current donor shortage. Comparable evaluation of risk factors for living donors should be investigated to improve this issue.

Patients and Methods: Our retrospective single-centre study analysed 158 patients with living kidney transplants performed between February 2006 and June 2012. We investigated the influence of donor risk factors (RF) including body mass index over $30 \mathrm{~kg} / \mathrm{m}^{2}$, age $>60$ years, active nicotine abuse and arterial hypertension on postoperative kidney function with focus on the recipients. This was measured for long-term survival and glomerular filtration rate (GFR) in a 5-year follow-up.

Results: Overall, out of 158 living donors, 84 donors were identified to have no risk factors, whereas 74 donors had at least one risk factor. We noted a significant higher delayed graft function $(\mathrm{p}=0.042)$ in the first 7 days after transplantation, as well as lower GFR of recipients of allografts with risk factors in the first-year after transplantation. In our long-term results, there was no significant difference in the functional outcome (graft function, recipient and graft survival) between recipients receiving kidneys from donors with no and at least one risk factors. In the adjusted analysis of subgroups of different risk factors, recipients of donors with "age over 60 years" at time of transplantation had a decreased transplant survival $(p=0.014)$.

Conclusion: Thus, a careful expansion for selection criteria for living donors with critical evaluation could be possible, but especially the age of the donors could be a limited risk factor.

Keywords: living donor nephrectomy, risk factor, selection criteria, survival, GFR

\section{Introduction}

Kidney transplantation is still the best option for patients with end stage kidney disease (ESKD) as patient survival rates are higher after kidney transplantation in comparison to patients remaining on dialysis. ${ }^{1}$ Furthermore, patients on dialysis have a threefold higher death rate and a more than sevenfold higher cardiovascular death rate compared to patients who received a kidney transplant. ${ }^{2}$

These risks must be evaluated in the context of further increasing waiting list in Germany. In 2018, 2.291 kidney transplantations were performed including 638 living donations (38.6\%). Furthermore, approximately 7.500 patients diagnosed with ESKD are currently on the waiting list for an organ donation in Germany. ${ }^{3}$

Organ transplantation after living donor nephrectomy (LDN) is one option in order to reduce the waiting time for a deceased organ and offers the access to 
transplantation. Furthermore, the outcome of living donation is better in contrast to deceased donation. ${ }^{4,5}$ To fulfill the requirements of living organ donation, patients need to have reached the legal age of 18 years to give voluntary consent and have the mental capacity to comprehend the risks and consequences of organ donation. ${ }^{6}$ For older patients, donor age alone is no absolute contraindication for an organ donation, but the donor should have at least a glomerular filtration rate (GFR) of $80 \mathrm{~mL} / \mathrm{min}$. Currently, the following contraindications for LDN include diabetes mellitus, uncontrolled hypertension, proteinuria $>300 \mathrm{mg} / 24 \mathrm{~h}$, age under 18 years, and a high risk for a thromboembolic event [5]. Contraindications include body mass index (BMI) $>35 \mathrm{~kg} / \mathrm{m}^{2}$, unsteady chronic infections including tuberculosis, hepatitis, and other mental health diseases, as well as microhaematuria without renal disease. ${ }^{7,8}$ Within the past decade, donor inclusion criteria have been adjusted to manage the disparity between organ supply and demand. These changes included age adjustments for deceased donors over the age of 60 years or over 50 years of age diagnosed with hypertension and reduced renal function with serum creatinine levels over $1.5 \mathrm{mg} / \mathrm{dl} .^{9,10}$ In 1999, Eurotransplant established the European Senior Transplant Program matching donors and recipients over 65 years of age. Fabrizii et al demonstrated that the use of kidneys with suboptimal quality from "marginal" donor demonstrated a comparable short- and long-term outcome for the recipients. ${ }^{11}$ Accordingly, a similar expansion of selection criteria for living transplantation, also known as expanded-criteria living donors (ECLDs), could improve access for many patients diagnosed with ESKD. ${ }^{12}$ ECLDs should consider donor age, GFR, BMI, impaired glucose tolerance and smoking history. Moreover, in living donors the kidneys vascular supply could influence recipients' outcome. ${ }^{13} \mathrm{~A}$ detailed evaluation of these risk factors and comorbidities is therefore essential to maintain donor safety as the mentioned risk factor are associated with increased rates of perioperative nephrectomy complications. ${ }^{14}$ Furthermore, extended criteria should not impair the outcome and graft function for the recipient. As there is little information available regarding the influence of extended criteria, this study aims to evaluate the influence of different ECLDs on the recipients' outcome following living kidney transplantation.

\section{Patients and Methods}

\section{Patients and Study Design}

This retrospective analysis utilized data from our institutional electronic database (TBaseC) of LDN at Charité Universitaetsmedizin Campus Mitte (Berlin, Germany) between February 2006 and June 2012. Paediatric LDN were excluded from this study. Data were collected and approved according to the guidelines of the institutional review board "Ethikkomission Charité" (Berlin, Germany) which based on the ICH Guideline for Good Clinical Practice and the declaration of the World Medical Association from 1964 (Helsinki) in their current version. Patient consent for review of medical records was not required because all data were de-identified. Therefore, all patient data were treated anonymously.

All living kidney donations were conducted voluntarily with a written informed consent of the donor in accordance to the Declaration of Istanbul before surgery. Every donor and recipient agreed for lifetime aftercare recording medical records in the electronic TBase (C) System for research. Our previous study describes the preoperative evaluation of living donors, the surgical techniques including laparoscopic approach via a 4-port transperitoneal access and our immunosuppression regime. ${ }^{13}$

\section{Outcome Parameters}

Donors were divided in two groups: donors without risk factors (RF) and donors with at least one RF. RF were defined as age over 60 years, arterial hypertension, active nicotine abuse and BMI over $30 \mathrm{~kg} / \mathrm{m} 2$. Operation details were measured surgery time, warm and cold ischemia and HLA mismatch.

Outcome parameters for both groups included postoperative GFR in $\mathrm{mL} / \mathrm{min}$, delayed graft function (DGF), graft function (GF) and graft- and patient survival. The DGF was suspected if haemodialysis was required within seven days postoperatively. ${ }^{15}$ GF was assessed by serumcreatinine, GFR and rejection rate after transplantation.

\section{Statistical Analysis}

Statistical analysis was performed using IBM SPSS Statistics 22 for Mac (SPSS, Inc., Chicago, IL, USA). Univariate parameters were analysed by $\chi^{2}$-Test and Fisher-Test. Continuous variables were tested with the non-paired Student's $t$-Test and the Mann-Whitney $U$-test for data with non-normal distribution. Kaplan-Meier estimates were used 
to calculate patient and transplant survival curves. We excluded all cases of recipients deceased with a functional transplant. A p-value of less than 5 percent was interpreted as statistically significant.

\section{Results}

\section{Demographic Data}

Overall, 158 living donor transplantations were performed between February 2006 and June 2012. One hundred forty-nine cases $(94.3 \%)$ had a primary transplantation, nine $(5.7 \%)$ cases a second transplantation and $23(14.6 \%)$ transplantations were performed prior to dialysis. In total, $\mathrm{n}=84$ donors had no $\mathrm{RF}$, whereas $\mathrm{n}=74$ donors had at least one or more RF with a mean followup of 33 months. The patient characteristics between donor groups are depicted in Table 1 and the recipient characteristics in Table 2. As shown in Table 1 there was no significant difference between the two groups in terms of time of donor nephrectomy, cold/warm ischemia time, HLA mismatch.

\section{Functional Outcome}

Among recipients of allografts with RF we detected a higher Delayed Graft Function in the first 7 days of transplantation (Table 1) with $12.1 \%$ in group with RF vs $3.6 \%$ with $\mathrm{RF}(\mathrm{p}=0.042)$ Although the recipients of kidneys from optimal donors had a significant higher GFR in the first-year post-transplantation, no significant difference was observed in the following years (Figure 1).

Figure 2 shows an adjusted analysis of post-operative GFR rates of recipients from allografts from donors with various risk factors three months after surgery. Only the group "Age over 60 years" had a significant reduced renal function $(\mathrm{p}<0.001)$.

During the follow up time, 50 recipients were identified to have a rejection in a biopsy result (32.3\%), however no difference was detected between the two study groups (donor group without $\mathrm{RF} \mathrm{n}=24$, donor group with $\mathrm{RF} \mathrm{n}=26$, $\mathrm{p}=0.453$ ). Overall graft survival of both groups was $93 \%$ without a significant difference between both groups $(\mathrm{p}=0.552)$ (Figure 1 Supplementary material). Only the subgroup of recipients of allografts from donors with "Age over 60 years" had a decreased graft survival with $75 \%$ in the follow up period compared to $94 \%$ in the group without RF $(\mathrm{p}=0.014)$ (Figure 2 Supplementary material). The overall survival of the recipients of the two groups with and without
Table I Means of Demographic Donor Characteristics and Operation Details

\begin{tabular}{|c|c|c|c|}
\hline Variables & $\begin{array}{l}\text { Donor without } \\
R F n=84\end{array}$ & $\begin{array}{l}\text { Donor with RF } \\
n=74\end{array}$ & P-value \\
\hline $\begin{array}{l}\text { Age, years (SD) } \\
\text { Gender, Male } \\
\text { BMI, kg/m² (SD) }\end{array}$ & $\begin{array}{l}45.4(24-60) \\
23(27.4 \%) \\
24.2(17.6-30.0)\end{array}$ & $\begin{array}{l}55.9(21-78) \\
29(39.2 \%) \\
26.7(18.0-37.3)\end{array}$ & $\begin{array}{l}0.0000 * \\
0.115 \\
0.0003^{*}\end{array}$ \\
\hline $\begin{array}{l}\text { Risk factors } \\
\text { Age }>60 \text { years } \\
\text { Arterial Hypertonus } \\
\text { BMI }>30 \mathrm{~kg} / \mathrm{m}^{2} \\
\text { Active nicotine abuse }\end{array}$ & $\begin{array}{l}- \\
- \\
- \\
-\end{array}$ & $\begin{array}{l}34(21.7 \%) \\
20(12.7 \%) \\
22(13.9 \%) \\
21(13.3 \%)\end{array}$ & \\
\hline $\begin{array}{l}\text { Vascularization } \\
\text { Number Arteries } \\
\text { I } \\
\geq 1 \\
\text { Unknown }\end{array}$ & $\begin{array}{l}66(78.6 \%) \\
15(17.9 \%) \\
2(2.4 \%)\end{array}$ & $\begin{array}{l}60(71.4 \%) \\
13(17.6 \%) \\
1(1.3 \%)\end{array}$ & 0.512 \\
\hline $\begin{array}{l}\text { Number Veins } \\
1 \\
2 \\
\text { Unknown }\end{array}$ & $\begin{array}{l}75(89.3 \%) \\
7(8.3 \%) \\
2(2.4 \%)\end{array}$ & $\begin{array}{l}71(95.9 \%) \\
2(2.7 \%) \\
1(1.3 \%)\end{array}$ & 0.123 \\
\hline $\begin{array}{l}\text { Operation } \\
\text { Characteristics }\end{array}$ & & & \\
\hline $\begin{array}{r}\text { Time of Surgery } \\
\text { nephrectomy (min) }\end{array}$ & 210.5 & 203.6 & 0.474 \\
\hline $\begin{array}{l}\text { Warm ischemia time } \\
\text { (min) }\end{array}$ & 2.48 & 2.46 & 0.902 \\
\hline Cold ischemia time (h) & 2.62 & 2.77 & 0.1608 \\
\hline HLA-Mismatch & & & \\
\hline MM-A (SD) & $0.88(0.12-1.6)$ & $0.84(0.12-1.56)$ & 0.700 \\
\hline MM-B (SD) & $1.13(0.35-1.83)$ & I.II (0.5-I.72) & 0.756 \\
\hline MM-DR (SD) & $0.98(0.30-1.66)$ & $0.97(0.33-1.65)$ & 0.987 \\
\hline$M M$ total (SD) & $2.99(1.36-4.62)$ & $2.92(1.40-4.50)$ & 0.678 \\
\hline DGF (SD) & $3(3.6 \%)$ & $9(12.1 \%)$ & $0.042^{*}$ \\
\hline
\end{tabular}

Notes: *Indicates P-values $<0.05$.

Abbreviations: RF, risk factor; $\mathrm{n}$, number; $\mathrm{BMI}$, body mass index; min, minutes; $\mathrm{h}$, hours; SD, standard deviation; HLA, human leukocyte antigen; MM-A, mismatch Loci A; MM-B, mismatch Loci B; MM-DR, mismatch Loci DR; DGF, delayed graft function.

$\mathrm{RF}$ in the maximum follow up period of 76 months was $97.4 \%(\mathrm{p}=0.232)$ (Figure 3 Supplementary material). The cause of death $(n=1)$ in the group without $\mathrm{RF}$ was a brain oedema ten days after transplantation. The causes of death $(n=3)$ in the group with RF were cardiac arrest, infection and cancer.

\section{Discussion}

In the present retrospective study, we found no difference in the functional outcome (graft function, survival) for the recipients receiving kidneys from donors without or with 
Table 2 Recipients Characteristics in Means, Percentage and Standard Deviation

\begin{tabular}{|c|c|}
\hline Variables & Recipient $n=\mid 58$ \\
\hline Age, Year (SD) & $43.6(29-58)$ \\
\hline Gender, Male n (\%) & $105(66.4)$ \\
\hline $\mathrm{BMI}, \mathrm{kg} / \mathrm{m}^{2}(\mathrm{SD})$ & $24.6(19.8-29.7)$ \\
\hline \multicolumn{2}{|l|}{ Cause of ESKD } \\
\hline Diabetes, n (\%) & $4(2.5)$ \\
\hline Art. Hypertonus, n (\%) & II (7) \\
\hline Glomerulonephritis, n (\%) & $25(15.8)$ \\
\hline Polycystic renal disease, $\mathrm{n}(\%)$ & $30(19)$ \\
\hline Congenital uropathy, n (\%) & $10(6.3)$ \\
\hline IgA Nephropathy, n (\%) & $25(15.8)$ \\
\hline FSGS, n (\%) & $9(5.7)$ \\
\hline Other, n (\%) & $44(27.8)$ \\
\hline \multicolumn{2}{|l|}{ Dialysis } \\
\hline No Dialysis, n (\%) & $23(14.6)$ \\
\hline Haemodialysis, n (\%) & $59(37.3)$ \\
\hline Peritoneal dialysis, n (\%) & $10(6.3)$ \\
\hline Unknown, n (\%) & $66(41.8)$ \\
\hline Duration of Dialysis, Months (SD) & $18(3-33)$ \\
\hline
\end{tabular}

Abbreviations: $n$, number; ESKD, end stage kidney disease; SD, standard deviation; IgA, immunoglobulin A; FSGS, focal segmental glomerulosclerosis.

risk factor in general. Although in the first years after transplantation the GFR was significantly reduced among recipients of allografts from donors with $\mathrm{RF}$, after 2 years the results were comparable. Nevertheless, in the subanalysis of graft survival outcome in subgroup risk factor "Age over 60 years" we found a statistical difference with a better functional outcome for recipient of allografts from younger living donors.

The topic of age remains always controversial as age alone should not be an absolute contraindication for organ donation. Nevertheless, a correlation between age and higher rates of comorbidities exists. An adverse effect of advanced donor age for allograft survival is already described for deceased organ transplantation. ${ }^{16}$ In a follow-up of five years Iordanous et al showed in their meta-analysis of 31 studies of living kidney donation a poorer outcome for graft survival in the group of donors aged over 60 years compared to younger donors. ${ }^{17}$ In contrast to these results, there are the promising findings in the European Senior Transplant Program, which allocated organs of donors over the age of 65 with end stage renal disease without an impairment of the survival or graft function. ${ }^{11} \mathrm{~A}$ recent review supports these results with an adequate outcome for older recipients, whereas younger patients with ESKD benefit from a younger LDN. ${ }^{18}$ The definition of "old" in the existing studies of ECLDs is unequal for the donors as the cut off differs between over 40 years up to 65 years of ages limiting their comparability.

Kidney transplantation of obese donors had no negative effect on renal graft function in our study. In 2000, Jacobs et al reported that the laparoscopic nephrectomy for obese patients with a mean BMI of $39 \mathrm{~kg} / \mathrm{m}^{2}$ is associated with more difficulties during surgery but had the same results in the recovery and graft function. ${ }^{14}$ Interestingly, results from the analysis of surgical- and ischemia time, showed no difference between donors with or without obesity (BMI $\geq 30 \mathrm{~kg} / \mathrm{m}^{2}$ ) as the technical circumstances of the nephrectomy itself were similar. This underlines the experiences of recent studies. ${ }^{19}$ After nephrectomy, the aftercare of obese donors is crucial, because these patients have an increased lifetime risk for developing ESKD. ${ }^{20,21}$ Even with normal predonation graft function, each kidney donor has a potential risk of developing chronic renal disease of at least stage one based on the classification of KDGIO 2012. ${ }^{22}$ Locke et al described that each unit of a pre-donation BMI above $27 \mathrm{~kg} / \mathrm{m}^{2}$ was associated with a seven percent higher risk of ESKD post-donation. ${ }^{23}$ Due to the lack of follow-up data of the donors, long-term renal function in these patients is unclear.

One of the most common cause of mortality of chronic renal failure is cardiovascular diseases, which could be influenced by the risk factors including hypertension and active nicotine abuse.

Smoking tobacco is one of the most common drugs abused by a mean rate of $25 \%$ in the German population. ${ }^{24}$ Although we did not verify an impairment on graft-or recipient survival, its negative effects can be found in the literature. ${ }^{25}$ Heldt et al showed a dose-dependent relationship between tobacco exposure and renal graft function. They showed a direct correlation between high level of tobacco exposure and reduced renal graft function by measuring post-donation GFR at one and six months posttransplantation in organ recipients. Other demographic characteristics including age, BMI and comorbidities such as hypertension and diabetes were equal. Nevertheless, our findings must be interpreted carefully, as dosing of donor tobacco use were not determined in our study but supposed to be relevant. 


\section{Means of GFR ( $\mathrm{ml} / \mathrm{min})$ of the recipients in the time of Follow up}

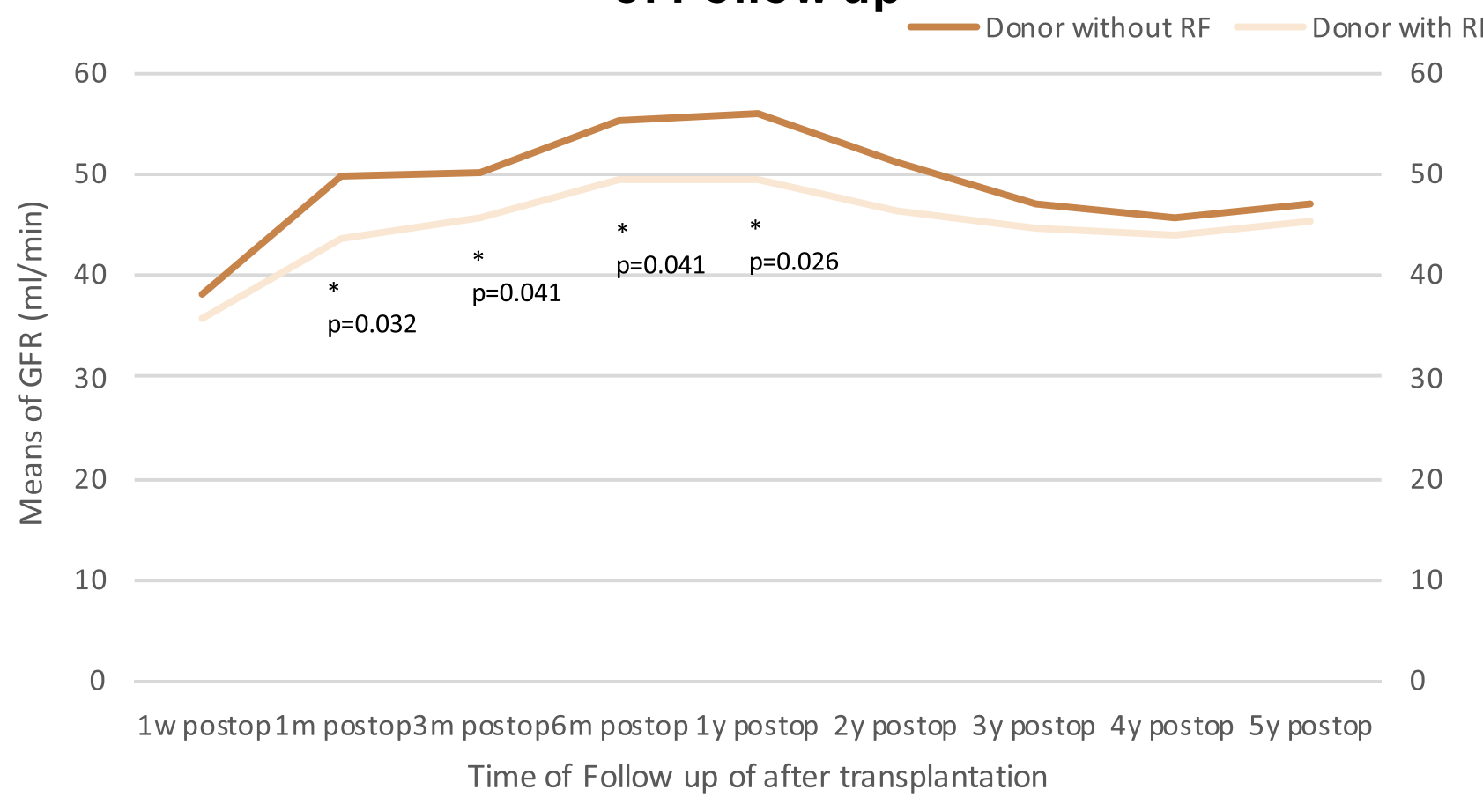

Figure I Postoperative Follow up of renal function of the recipients after transplantation.

Note: *Indicates P-values $<0.05$.

Abbreviations: GFR, glomerular filtration rate; RF, risk factor; w, week; m, months; y, years.

Donors diagnosed with arterial hypertension with blood pressures over 140/90 $\mathrm{mmHg}$ are meant to be suboptimal for LDN according to the Amsterdam Forum. ${ }^{6}$ We assigned all donors with at least one blood pressure medication to the group with risk factors without further consideration. According to the results of the review of Iordanous et al considering similar selection criteria for arterial hypertension, we could not determine a negative impact on graft function. ${ }^{17}$ Both of the two mentioned studies in the review analysed the post-donation GFR and showed a comparable function in the recipient one year post-transplantation in the optimal and suboptimal donor group. ${ }^{26,27}$ Regarding the long-term effects on blood pressure of the donor, our findings are limited as the focus is on the recipients graft survival. The evaluation of the cardiovascular risks of living donors are estimated variables based on literature. Some studies detected higher prevalence of hypertension up to $150 \%$ compared to the control group, ${ }^{28,29}$ whereas other research did not identify relevant differences. ${ }^{30,31}$ Based on a more frequent monitoring post-LDN, higher prevalence of hypertension in the donor groups could be expected.
However, our study must be interpreted in the context of its limitations. Our data supports existing research and efforts of improving living kidney donation but do not confirm a harmless expansion of selection. The small population and a mean follow up of 33 months after transplantation may not allow identifying long-term effects of expanded criteria for donors. Concerning this matter Muzaale et al showed 2016 their 20-year follow up those donor-dependent subclinical risk factors for ESKD as hypertension or age could jeopardize the graft survival. ${ }^{21}$ By dichotomizing the extended criteria (with $\mathrm{RF}$ /without RF), potential confounding of the risk factors is maybe neglected and should be further analysed.

\section{Conclusion}

Finally, our findings demonstrated a worse graft function of allografts from high-risk donors in the first year. In the long-term results, only the group of age over 60 had a negative impact in graft survival. Thus, an expansion of criteria for living kidney donors may improve the current lack of organs, however a preoperative evaluation and allocation of donors and recipients is absolute essential. As we have focussed on the recipient's outcome it is equally 


\section{Means of GFR ( $\mathrm{ml} / \mathrm{min}$ ) of the recipients of donor with and without RF 3 months after transplantation}

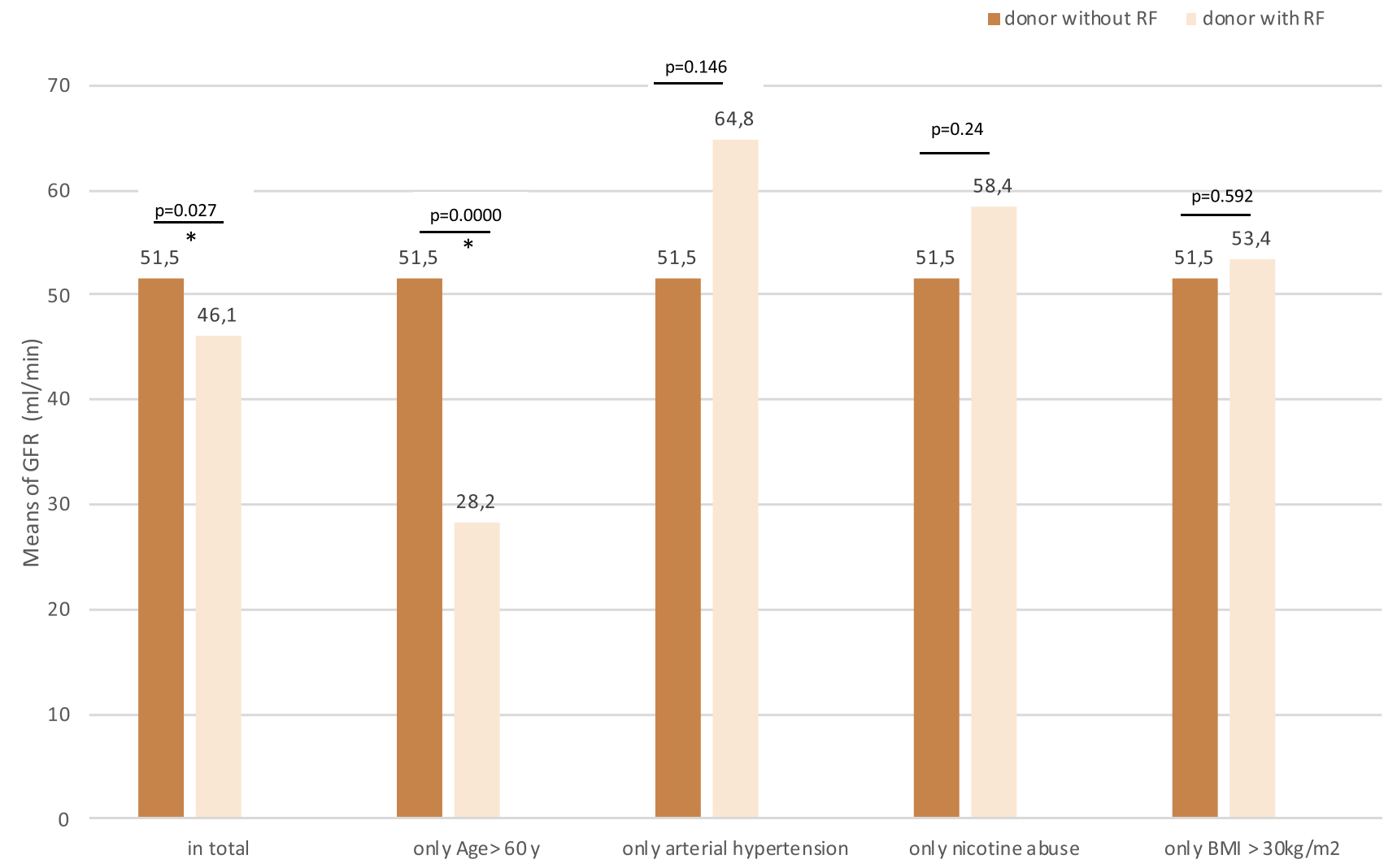

Figure 2 Subanalysis of glomerular function of the recipients 3 months after transplantation.

Note: *Indicates P-values $<0.05$.

Abbreviations: GFR, glomerular filtration rate; RF, risk factor; BMI, body mass index; $y$, years.

necessary to evaluate the impact for the donor and potential risks for ESKD in further research.

\section{Disclosure}

The authors report no conflicts of interest in this work.

\section{References}

1. Oniscu GC, Brown H, Forsythe JL. Impact of cadaveric renal transplantation on survival in patients listed for transplantation. $J \mathrm{Am}$ Soc Nephrol. 2005;16(6):1859-1865. doi:10.1681/ASN.2004121092

2. Kaplan B, Meier-Kriesche HU. Death after graft loss: an important late study endpoint in kidney transplantation. Am J Transplant. 2002;2 (10):970-974. doi:10.1034/j.1600-6143.2002.21015.x

3. Organ Spende. Annual report 2018 of the German Foundation for Organ Transplantation (DSO). Uniform overall report with nationwide figures broken down by DSO regions. Available from: https://dso.de/ SiteCollectionDocuments/DSO_Jahresbericht_2018.pdf. Accessed August 10, 2020.

4. Reese PP, Boudville N, Garg AX. Living kidney donation: outcomes, ethics, and uncertainty. Lancet Neurol. 2015;385(9981):2003-2013. doi:10.1016/S0140-6736(14)62484-3
5. Cecka JM. The UNOS renal transplant registry. Clin Transpl. 2002;1-20.

6. Delmonico F. A report of the amsterdam Forum on the care of the live kidney donor: data and medical guidelines. Transplantation. 2005;79(6 Suppl):S53-S66. doi:10.1097/01.TP.0000157343.27949.9F

7. Lennerling A, Loven C, Dor FJ, et al. Living organ donation practices in Europe - results from an online survey. Transpl Int. 2013;26 (2):145-153. doi:10.1111/tri.12012

8. Ahmadi AR, Lafranca JA, Claessens LA, et al. Shifting paradigms in eligibility criteria for live kidney donation: a systematic review. Kidney Int. 2015;87(1):31-45. doi:10.1038/ki.2014.118

9. Maggiore U, Oberbauer R, Pascual J, et al. Strategies to increase the donor pool and access to kidney transplantation: an international perspective. Nephrol Dial Transplant. 2015;30(2):217-222. doi:10. 1093/ndt/gfu2 12

10. Gaston RS, Danovitch GM, Adams PL, et al. The report of a national conference on the wait list for kidney transplantation. Am J Transplant. 2003;3(7):775-785. doi:10.1034/j.1600-6143. 2003.00146.x

11. Fabrizii V, Kovarik J, Bodingbauer M, Kramar R, Horl WH, Winkelmayer WC. Long-term patient and graft survival in the eurotransplant senior program: a single-center experience. Transplantation. 2005;80(5):582-589. doi:10.1097/01.tp.00001683 40.05714 .99 
12. Lim HJ, Jambaldorj E, Lee Y, et al. Increasing use of the expanded criteria for living kidney donation and good outcomes of living kidney donors in Korea. Transplant Proc. 2016;48(7):2407-2411. doi:10.1016/j. transproceed.2016.02.091

13. Friedersdorff F, Werthemann P, Cash H, et al. Outcomes after laparoscopic living donor nephrectomy: comparison of two laparoscopic surgeons with different levels of expertise. BJU Int. 2013;111 (1):95-100. doi:10.1111/j.1464-410X.2012.11348.x

14. Jacobs SC, Cho E, Dunkin BJ, et al. Laparoscopic nephrectomy in the markedly obese living renal donor. Urology. 2000;56(6):926-929. doi:10.1016/S0090-4295(00)00813-X

15. Yarlagadda SG, Coca SG, Garg AX, et al. Marked variation in the definition and diagnosis of delayed graft function: a systematic review. Nephrol Dial Transplant. 2008;23(9):2995-3003. doi:10.1093/ndt/ gfn158

16. Mezrich JD, Pirsch JD, Fernandez LA, et al. Differential outcomes of expanded-criteria donor renal allografts according to recipient age. Clin J Am Soc Nephrol. 2012;7(7):1163-1171. doi:10.2215/CJN.00150112

17. Iordanous Y, Seymour N, Young A, et al. Recipient outcomes for expanded criteria living kidney donors: the disconnect between current evidence and practice. Am J Transplant. 2009;9(7):1558-1573. doi:10.1111/j.1600-6143.2009.02671.x

18. Lam NN, Garg AX. Acceptability of older adults as living kidney donors. Curr Opin Nephrol Hypertens. 2016;25(3):245-256. doi:10.1097/MNH.0000000000000215

19. Uguz A, Unsal MG, Unalp OV, et al. Is a high body mass index still a risk factor for complications of donor nephrectomy? Transplant Proc. 2015;47(5):1291-1293. doi:10.1016/j.transproceed.2015.04.061

20. Steiner RW. The risks of living kidney donation. $N$ Engl J Med. 2016;374(5):479-480. doi:10.1056/NEJMe1513891

21. Muzaale AD, Massie AB, Anjum S, et al. Recipient outcomes following transplantation of allografts from live kidney donors who subsequently developed end-stage renal disease. Am J Transplant. 2016;16(12):3532-3539. doi:10.1111/ajt.13869

22. Muzaale AD, Massie AB, Wang MC, et al. Risk of end-stage renal disease following live kidney donation. JAMA. 2014;311(6):579-586. doi:10.1001/jama.2013.285141
23. Locke JE, Reed RD, Massie A, et al. Obesity increases the risk of end-stage renal disease among living kidney donors. Kidney Int. 2017;91(3):699-703. doi:10.1016/j.kint.2016.10.014

24. Kotz D, Böckmann M, Kastaun S. The use of tobacco, E-cigarettes, and methods to quit smoking in Germany. Dtsch Arztebl Int. 2018;115(14):235-242. doi:10.3238/arztebl.2018.0235

25. Heldt J, Torrey R, Han D, et al. Donor smoking negatively affects donor and recipient renal function following living donor nephrectomy. $A d v$ Urol. 2011;2011:929263. doi:10.1155/2011/929263

26. Srivastava A, Sinha T, Varma PP, et al. Experience with marginal living related kidney donors: are they becoming routine or are there still any doubts? Urology. 2005;66(5):971-975. doi:10.1016/j. urology.2005.05.005

27. Textor SC, Taler SJ, Driscoll N, et al. Blood pressure and renal function after kidney donation from hypertensive living donors. Transplantation. 2004;78(2):276-282. doi:10.1097/01.TP.0000128 168.97735.B3

28. Doshi MD, Goggins MO, Li L, Garg AX. Medical outcomes in African American live kidney donors: a matched cohort study. Am $J$ Transplant. 2013;13(1):111-118. doi:10.1111/j.1600-6143.2012. 04303. $\mathrm{x}$

29. Garg AX, Prasad GV, Thiessen-Philbrook HR, et al. Cardiovascular disease and hypertension risk in living kidney donors: an analysis of health administrative data in Ontario, Canada. Transplantation. 2008;86(3):399-406. doi:10.1097/TP.0b013e31817ba9e3

30. Janki S, Klop KW, Dooper IM, Weimar W, Ijzermans JN, Kok NF. More than a decade after live donor nephrectomy: a prospective cohort study. Transpl Int. 2015;28(11):1268-1275. doi:10.1111/ tri. 12589

31. Yalin SF, Trabulus S, Seyahi N, Cengiz M, Cicik ME, Altiparmak MR. Ambulatory blood pressure monitoring in living kidney donors: what changes in 10 years? Clin Transplant. 2018;32 (4):e13224. doi:10.1111/ctr.13224
Therapeutics and Clinical Risk Management

\section{Publish your work in this journal}

Therapeutics and Clinical Risk Management is an international, peerreviewed journal of clinical therapeutics and risk management, focusing on concise rapid reporting of clinical studies in all therapeutic areas, outcomes, safety, and programs for the effective, safe, and sustained use of medicines. This journal is indexed on PubMed Central, CAS,

\section{Dovepress}

EMBase, Scopus and the Elsevier Bibliographic databases. The manuscript management system is completely online and includes a very quick and fair peer-review system, which is all easy to use. Visit http://www.dovepress.com/testimonials.php to read real quotes from published authors. 